\title{
Isothermal Heat Treatment of AISI 430 Ferritic Stainless Steel after High Temperature Gas Nitriding
}

\author{
Sang-Jun Park, Jung-Min Kim*, Hee-Jae Kang*, Chang-Yong Kang**, \\ Yung-Hee Kim*, Jang-Hyun Sung*,† \\ ILJIN GLOBAL, R\&D Center, Materials Engineering Dept. 128-5 Samsung-dong, Kangnam-Gu, Seoul 135-875, Korea \\ ${ }^{*}$ Department of Materials Science and Engineering, Dong-A University, \\ 840 Hadan-Dong, Saha-gu, Busan 604-714, Korea \\ **Division of Materials Science and Engineering, Pukyong National University, Busan, Korea
}

\begin{abstract}
It has been known that the ferritic stainless steel can be changed to martensitic stainless steel when nitrogen is added. However the high hardness of martensitic stainless steel prevents the plastic deformation. In this study, instead of martensite, the surface microstructure was changed into nitrogen pearlite to increase the plastic deformation easily by isothermal heat treatment after high temperature gas nitriding (HTGN) the AISI 430 ferritic stainless steel. The isothermal treatment was carried out at $780^{\circ} \mathrm{C}$ for 4,6 , and $10 \mathrm{hrs}$, respectively, after $\mathrm{HTGN}$ treatment at $1100^{\circ} \mathrm{C}$ for $10 \mathrm{hrs}$. The surface layer of isothermal-treated steel appeared nitrogen pearlite composed with fine chromium nitride and ferrite. Hence, the interior region that was not affected by nitrogen permeation exhibited ferrite phase. When quenching the isothermal treated steel at $1100^{\circ} \mathrm{C}$, martensitic phase formed at the surface layer. The hardness of surface layer of isothermal-treated steel and quenched steel measured the value of $150 \sim 240 \mathrm{Hv}$ and $630 \mathrm{Hv}$, respectively.
\end{abstract}

(Received March 27, 2012; Revised April 13, 2012; Accepted April 20, 2012)

Key words: AISI430 ferrite stainless steel, HTGN, Isothermal treatment, Nitrogen pearlite

\section{Introduction}

High temperature gas nitriding (HTGN) is a nitrogen permeation process by heat treating in an atmosphere of nitrogen gas at high temperature $[1,2]$. The depth of nitrogen permeation is dependent on the amount of alloying elements, the pressure of nitrogen gas, HTGN treatment temperature and time [3]. HTGN treatment has usually been applied to the austenitic, martensitic and duplex stainless steels, which have high $\mathrm{Cr}$ contents [4-7]. However, ferrite stainless steels have not been applied the HTGN treatment due to the low nitrogen solubility in the ferrite phase. Recently, a study on the HTGN treatment has progressed for ferrite stainless steel $[8$, 9]. After cooling the HTGN-treated ferritic stainless steel, even if air cooling, the surface phase is transformed into hard martensitic phase $[9,10]$. This prevents the plastic deformation after HTGN treatment.
Therefore, it is difficult to deform the finishing products that requires deformation or machining. In order to improve the ability of plastic deformation, instead of hard martensite case, if we fabricate the soft surface layer by adjusting the cooling rate from HTGN treatment temperature, plastic deformations such as forging, rolling etc. may be facilitated. After plastic deformation, the end-user could be achieved a hard martensitic surface layer simply by cooling the solution-annealed ferritic stainless stee.

This study, using AISI 430 ferritic stainless steel, was to investigate the formation of soft surface layer by isothermal transformation heat treatment (IT) after HTGN treatment to facilitate the plastic deformation. After IT treatment, formation of matrenstic phase at the surface layer were examined by solution annealing (SA). Thus the precipitates appeared after IT treatment and formation of hard martenstic phase were examined.

\footnotetext{
${ }^{\dagger}$ Corresponding author. E-mail : jhsung@dau.ac.kr
} 
Table 1. Chemical composition of the AISI 430 steel (wt.\%)

\begin{tabular}{c|c|c|c|c|c|c|c|c}
\hline Specimen & $\mathrm{C}$ & $\mathrm{Si}$ & $\mathrm{Mn}$ & $\mathrm{P}$ & $\mathrm{S}$ & $\mathrm{Cr}$ & $\mathrm{Ni}$ & $\mathrm{Fe}$ \\
\hline AISI 430 & 0.04 & 0.26 & 0.40 & - & - & 16.26 & 0.1 & Bal. \\
\hline
\end{tabular}

\section{Experimental Procedure}

The $3 \mathrm{~mm}$ thick plate of AISI 430 ferritic stainless steel was prepared. Table 1 shows the chemical composition of the ferrite stainless steel. The plate was cut into dimensions of $15 \mathrm{~mm} \times 60 \mathrm{~mm} \times 3 \mathrm{~mm}$. The steel was HTGN heat-treated using a pressure changeable furnace in an atmosphere containing $1 \mathrm{~kg} / \mathrm{cm}^{2}$ nitrogen gas at $1100^{\circ} \mathrm{C}$ for $10 \mathrm{hrs}$, followed by isothermal heat-treated (IT) at $780^{\circ} \mathrm{C}$ for 4,6 and $10 \mathrm{hrs}$ (HTGN-IT). Cooling rate from HTGN temperature to IT temperature was $10^{\circ} \mathrm{C} / \mathrm{min}$. After IT treatment, the steel was solution annealed (SA) at $1100^{\circ} \mathrm{C}$ for $1 \mathrm{hr}$, and then quenched in the water. After heat treatment at each stage, the microstructure was observed by using optical microscope and SEM-EDS analysis after polishing and etching the steel in the solution of $15 \mathrm{ml}$ hydrochloric acid, $10 \mathrm{ml}$ nitric acid, $10 \mathrm{ml}$ acetic acid and $30 \mathrm{ml}$ ethanol. Identification of phases was analyzed by using X-ray diffractometer (XRD) with $\mathrm{Cu}-\mathrm{K} \alpha$ radiation. Nitrogen, carbon and $\mathrm{Cr}$ contents from the surface to the interior were analyzed by using GDA after HTGN-IT treatment. Hardness measurement was carried out under the load of $100 \mathrm{~g}$ on cross-section from the surface to the interior by using microVickers hardness tester.

\section{Results and Discussion}

3.1 Effect of High Temperature Gas Nitriding-isothermal Heat Treatment on the Phase Change.

Fig. 1 shows OM image of as-received AISI 430 ferritic stainless steel. The ferrite grains were arranged to the direction of rolling.

Fig. 2. shows Fe-Cr-N phase diagram at $1100^{\circ} \mathrm{C}$.

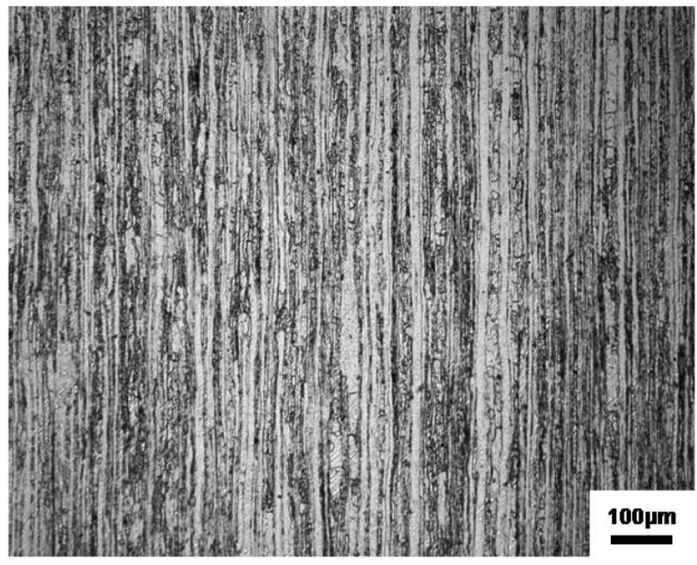

Fig. 1. Optical micrograph of AISI 430 ferritic stainless steel.

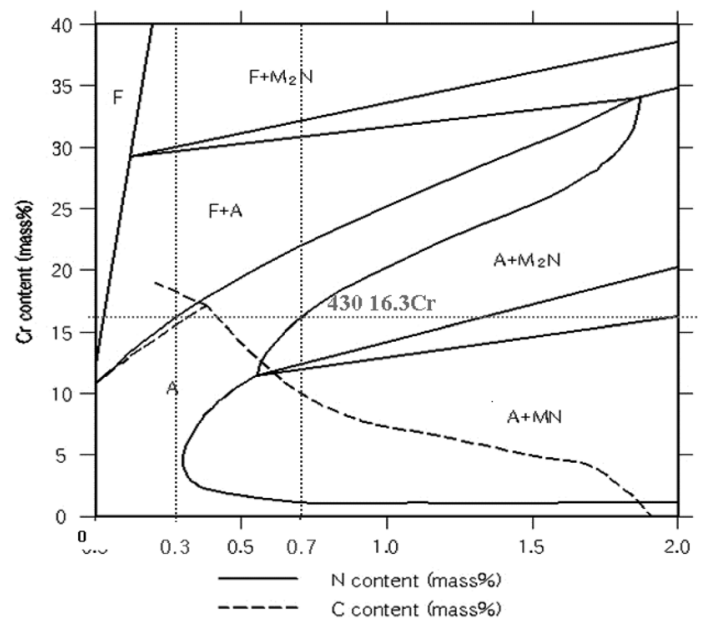

Fig. 2. Fe-Cr-N phase diagram at $1100^{\circ} \mathrm{C}$ derived by ThermoClac [3].

With increasing nitrogen and $\mathrm{Cr}$ contents, the region of austenite phase field is increased. And the austenite single phase field is shown from 0.3 to $0.7 \% \mathrm{~N}$ at the $16.3 \% \mathrm{Cr}$. Austenite plus $\mathrm{M}_{2} \mathrm{~N}$ phases can be seen above $0.7 \% \mathrm{~N}$.

Fig. 3 shows the cross-sectional view of OM micrographs of isothermal heat treated steel at $780^{\circ} \mathrm{C}$ for 1,4 and $10 \mathrm{hrs}$ after cooling to $10^{\circ} \mathrm{C} / \mathrm{min}$ 


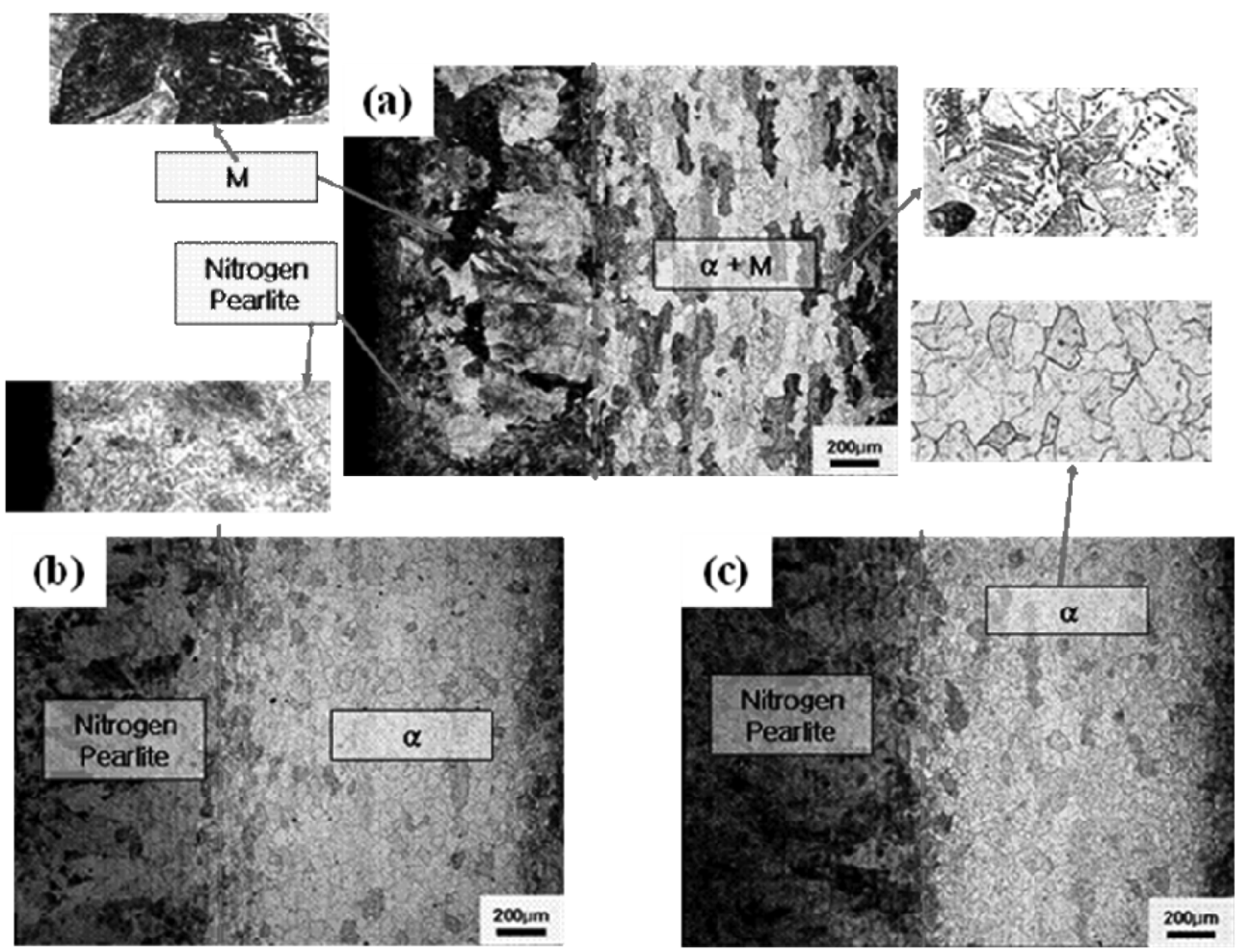

Fig. 3. Optical micrographs of isothermal transformation heat treated steel at $780^{\circ} \mathrm{C}$ after high temperature gas nitriding at $1100^{\circ} \mathrm{C}$ in AISI 430 ferritic steel. IT treatment time: a) $\left.\left.1 \mathrm{hr} \mathrm{b}\right) 4 \mathrm{hrs} \mathrm{c}\right) 10 \mathrm{hrs}$.

for the HTGN-treated steel at $1100^{\circ} \mathrm{C}$ for $10 \mathrm{hrs}$.

Layered nitrogen pearlite [11] with the $800 \mu \mathrm{m}$ depth and small quantity of martensite between nitrogen pearlite was formed at the surface layer for 1 hour IT treatment. On the other hand, the interior region appeared ferrite and martensite (a). For the isothermal heat-treated steels for 4 and 10 hours, nitrogen pearlite without martensite phase was formed with the depth of $800 \mu \mathrm{m}$ from the surface, and the inside regions showed only ferrite phases. Thus, $\gamma+\mathrm{M}_{2} \mathrm{~N}$ phases existed at the HTGN temperature, as shown in Fig. 2, was changed into $\alpha+\mathrm{M}_{2} \mathrm{~N}$ nitrogen pearlite during IT treatment at $780^{\circ} \mathrm{C}$.

To identify the phase appeared at the surface of HTGN-IT treated steel, X-ray diffraction analysis was applied as shown in Fig. 4. Strong peaks and weak $\mathrm{Cr}_{2} \mathrm{~N}$ peaks were detected. This implies that

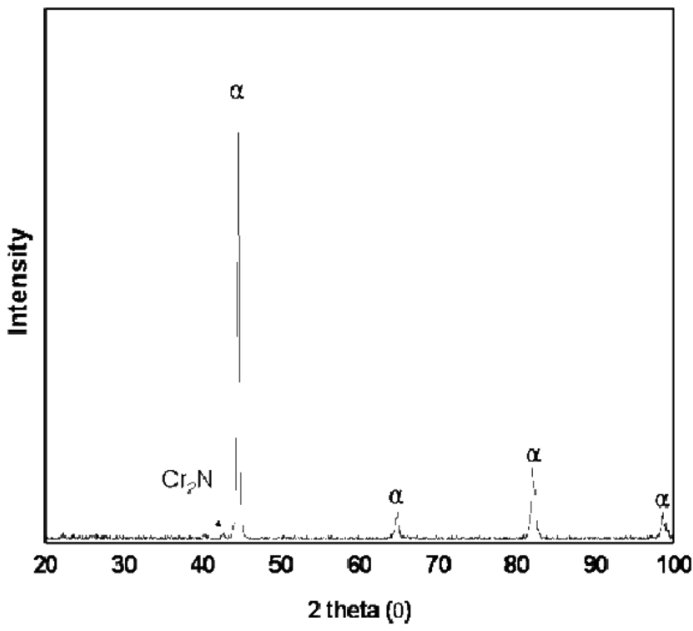

Fig. 4. XRD analysis result of HTGN-IT treated AISI 430 steel.

the $\mathrm{Cr}_{2} \mathrm{~N}$ was formed in the matrix of ferrite during IT treatment.

Fig. 5 shows SEM micrographs and EDS analysis 

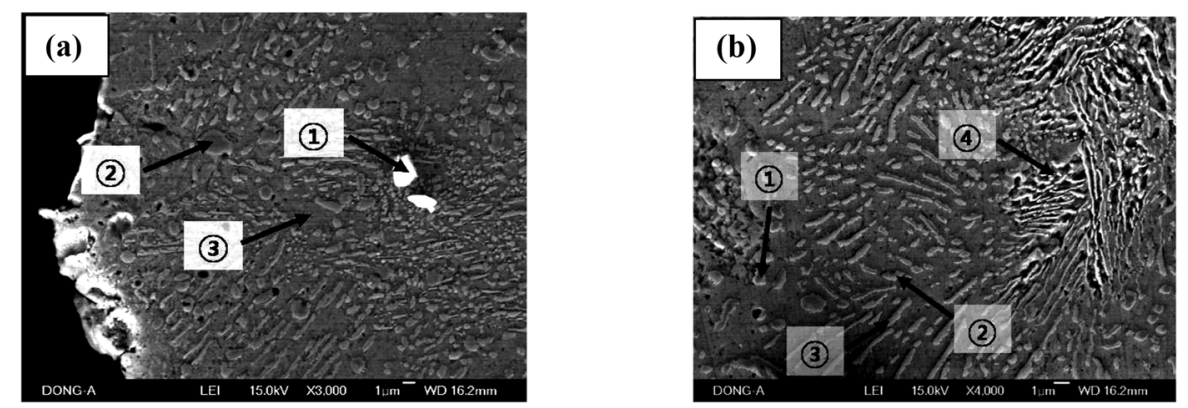

\begin{tabular}{|c|c|c|c|c|c|c|}
\hline & $\mathbf{C}$ & $\mathbf{N}$ & $\mathbf{S i}$ & $\mathbf{C r}$ & $\mathbf{M o}$ & $\mathbf{F e}$ \\
\hline$(1)$ & - & 6.08 & - & 12.84 & - & 81.08 \\
\hline$(2)$ & - & 0.32 & - & 21.61 & - & 78.06 \\
\hline$(3)$ & - & 0.79 & - & 25.26 & - & 73.95 \\
\hline
\end{tabular}

\begin{tabular}{|c|c|c|c|c|c|c|}
\hline & $\mathbf{C}$ & $\mathbf{N}$ & $\mathbf{S i}$ & $\mathbf{C r}$ & $\mathbf{M o}$ & $\mathbf{F e}$ \\
\hline (1) & - & 2.18 & - & 29.30 & - & 68.51 \\
\hline$(2)$ & 1.33 & 2.63 & - & 35.77 & - & 61.60 \\
\hline$(3)$ & - & 0.40 & - & 25.87 & - & 73.73 \\
\hline (4) & - & 1.39 & - & 31.33 & - & 67.28 \\
\hline
\end{tabular}

Fig. 5. SEM micrographs and EDS analysis results of the surface region after HTGN-IT treatment. IT-treated at $780^{\circ} \mathrm{C}$ for $\left.10 \mathrm{hrs}: \mathrm{a}\right)$ surface b) near surface.

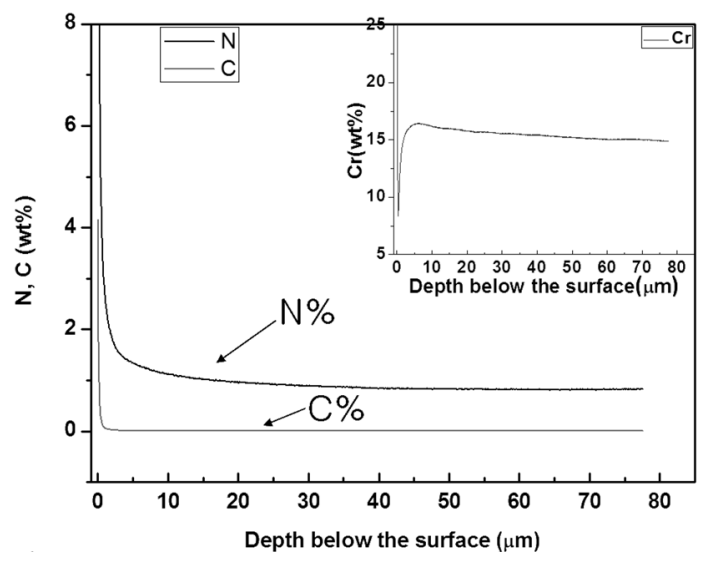

Fig. 6. GDS analysis result of depth below the surface after HTGN-IT treatment.

result of the surface layer after HTGN-IT treatment. Pearlite like structure, which is called nitrogen pearlite, composed with nitrides and ferrite, was observed [11]. EDS analysis showed that the precipitates were chromium nitrides.

Fig. 6 shows the variation of nitrogen, carbon and $\mathrm{Cr}$ contents with increasing depth below the surface. Nitrogen content decreased steeply at the outmost surface layer, and decreased gradually, reaching $0.96 \% \mathrm{~N}$ at the $20 \mu \mathrm{m}$ and $0.84 \% \mathrm{~N}$ at the $80 \mu \mathrm{m}$ from the surface. Also, in Fig. 2, austenite $+\mathrm{M}_{2} \mathrm{~N}$ phases can be seen above $0.7 \% \mathrm{~N}$ at the
$16.3 \% \mathrm{Cr}$. On considering the nitrogen content of HTGN-IT treated specimen as shown in Fig. 5, it is sure that the nitrogen content may be over $0.7 \%$ at the HTGN temperature. Therefore, it is said that the austenite $+\mathrm{M}_{2} \mathrm{~N}$ phases at HTGN temperature was changed to ferrite $+\mathrm{M}_{2} \mathrm{~N}$ phases during cooling from HTGN temperature to $780^{\circ} \mathrm{C}$. During nitrogen permeates from the surface to the interior, a substitutional element $\mathrm{Cr}$ also moves from the interior to the surface due to strong affinity between nitrogen atoms and $\mathrm{Cr}$ atoms [12]. This made a $\mathrm{Cr}$ depletion zone at the near surface region as shown in the upper part of the Figure.

Fig. 7 shows the hardness variation with depth below the surface after HTGN-IT treatment. The hardness decreased with depth, and the maximum value of $\sim 240 \mathrm{Hv}$ appeared after isothermal treatment for $4 \mathrm{hrs}$ and $6 \mathrm{hrs}$. Also, minimum hardness value measured $\sim 130 \mathrm{Hv}$ at the distance of $1500 \mu \mathrm{m}$ from the surface. From the surface hardness and microstructure of HTGN-IT treated AISI 430 steel, these hardness values are enough to deform plastically [13]. In this figure, the depth of nitrogen permeation can be deduced from the hardness as $\sim 1200 \mu \mathrm{m}$. 


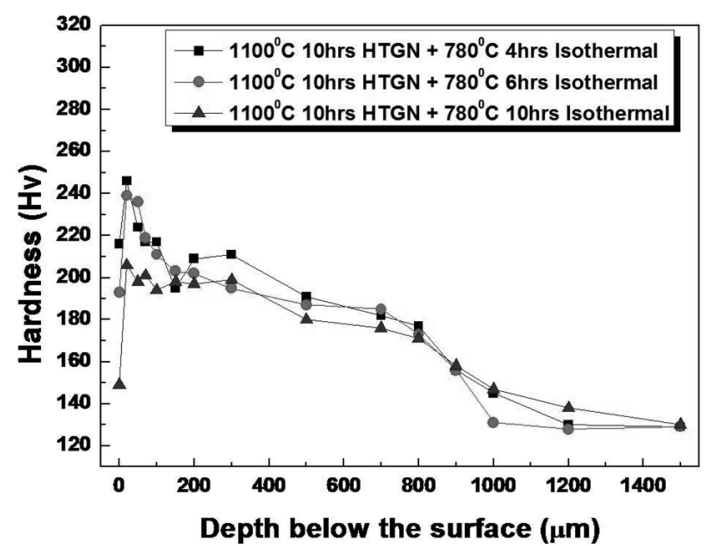

Fig. 7. Hardness as a function of depth below the surface after HTGN-IT treatment.

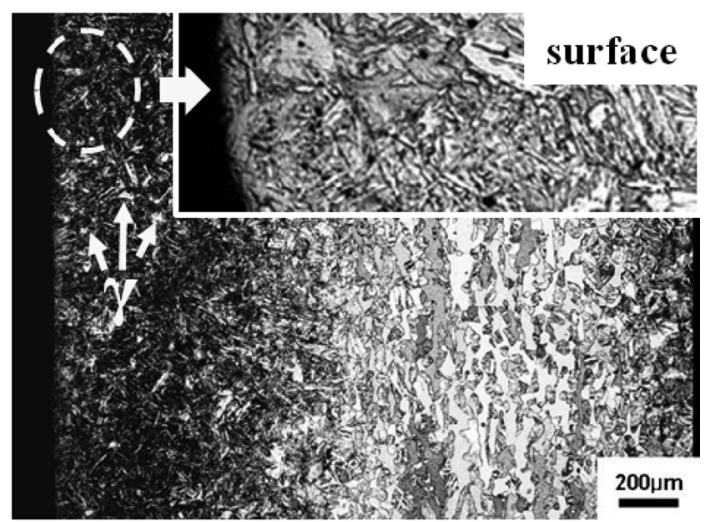

Fig. 8. Optical micrographs of SA-treated steels at the surface region after HTGN-IT treatment.

3.2 Effect of Solution Annealing on the Phase Change for the HTGN-IT Treated AISI430 Steel.

Fig. 8 shows OM images of the solution-annealed (SA) steel at $1100^{\circ} \mathrm{C}$ for $1 \mathrm{~h}$ after HTGN-IT treatment. Martensite phase appeared at the surface layer, however ferrite phase was shown in the interior region. White phase that could not distinguish the phase with $\mathrm{OM}$ were also observed in the martensite matrix.

Fig. 9 shows x-ray diffraction analysis result to identify the phase appeared at the surface layer of SA-treated steel. The strong $\alpha$ ' peaks and weak $\gamma$ peaks were observed. That is, martensite and

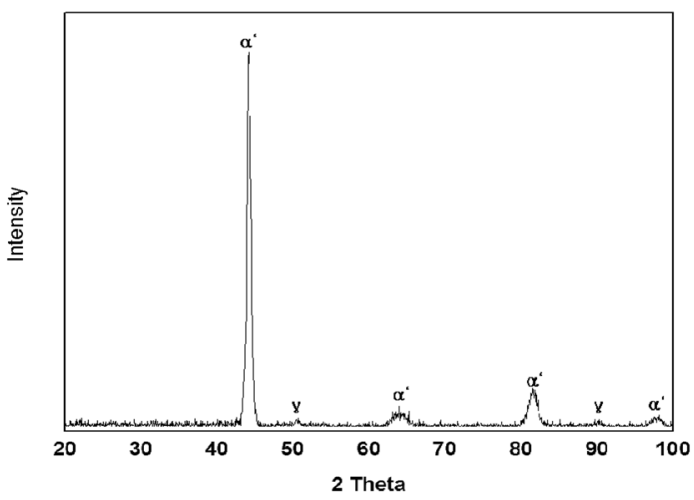

Fig. 9. XRD analysis result of SA-treated steels after HTGN-IT treatment.

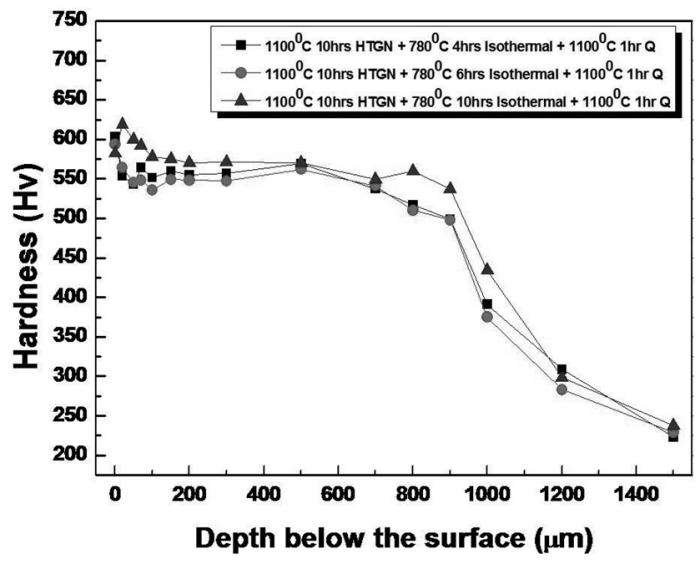

Fig. 10. Hardness as function of the depth below the surface of SA-treated steels after HTGN-IT treatment.

retained austenite were formed after SA treatment. The white phase observed in the matrix from $\mathrm{OM}$ (Fig. 8) might be a retained austenite.

Fig. 10 shows the hardness variation of SA-treated steel after HTGN-IT treatment. Hardness appeared high at near surface, were showed nearly constant with the value of $\sim 570 \mathrm{Hv}$ up to $800 \mu \mathrm{m}$. After that, the hardness decreased steeply. The effect of ITtreatment time on the hardness value was small.

\section{Conclusions}

Isothermal heat treatment (IT) after high temperature gas niitriding (HTGN) was carried out 
to find a soft surface by using AISI 430 ferritic stainless steel. After IT treatment, solution annealing (SA) was performed to obtain a hard martensitc phase at the surface layer. The results obtained are summarized as follows.

1. HTGN-IT treatment showed nitrogen pearlite with the alternative structure between ferrite and nitrides $\left(\mathrm{Cr}_{2} \mathrm{~N}\right)$. The hardness of HTGN-IT treated steel decreased gradually after showing the maximum value of $240 \mathrm{Hv}$.

2. Variation of nitrogen content after HTGN-IT treatment appeared the value of $0.96 \% \mathrm{~N}$ at the $20 \mu \mathrm{m}$ and $0.84 \% \mathrm{~N}$ at the $80 \mu \mathrm{m}$.

3. Solution annealing after the HTGN-IT treatment showed the microstructure of martensite and retained austenite at the surface layer. The hardness of this martensitic phase region measured the value of $\sim 570 \mathrm{Hv}$.

\section{Acknowledgement}

This work was supported by grant No. RT104-0103 from the Regional Technology Innovation Program of the Ministry of Knowledge Economy (MKE).
1. D. K. Yoo and J. H. Sung : J. of the Korean Society for Heat Treatment, 19(1) (2006) 3-9.

2. D. K. Yoo and J. H. Sung : J. of the Korean Society for Heat Treatment, 19(2) (2006) 83-89.

3. V. G. Garvriljuk, H. Berns : "High Nitrogen steels" Springer, Berlin-New York (1999) pp. 205207

4. H. J. Lee, J. H. Kong, H. W. Lee, D. K. Yoo, C. Y. Kang, and J. H. Sung : J. of the Korean Society for Heat Treatment, 20(2) (2007) 84-93.

5. J. H. Kong, D. K. Yoo, J. H. Park, H. W. Lee and J. H. Sung : J. of the Korean Society for Heat Treatment, 20(6) (2007) 311-317.

6. D. K. Yoo, J. H. Kong, H. J. Lee, J. H. Sung and H. W. Lee : Korean J. of Metals and Materials, 46(11) (2008) 678-682.

7. H. W. Lee, J. H. Kong, D. J. Lee, H. Y. On and J. H. Sung : Materials Design, 30 (2009) 1691-1696.

8. D. K Yoo, H. J Lee, C, Y. Kang, K. H. Kim, Y. H. Kim and J. H. Sung : Solid State Phenomena, 118 (2006) 149-154.

9. J. H. Sung, J. H. Kong, D. K Yoo, H. Y On, D. J. Lee and H. W. Lee : Materials Science and Engineering A, 489 (2008) 38-43.

10. J. H. Kong, D. K. Yoo, H. W. Lee, Y. H. Kim and J. H. Sung : J. of the Korean Society for Heat Treatment, 20(6) (2007) 323-328.

11. H. Berns, \& S. Siebert : ISIJ International, 36 (1996) 927-931.

12. H. J. Lee, J. H. Kong, D. K Yoo, Y. C. Park and J. H Sung : Advanced Materials Research Vols. 26 28 (2007) 1303-1306.

13. J. H Sung, J. M. Kim and H. J. Kang : Korea Patent, Application Number 10-2011-0110085.

\section{References}

